AUFKLÄRUNG, João Pessoa, v.7, n.esp., Nov., 2020, p.111-122

Q

Licença: Creative Commons 4.0 International (CC BY 4.0)

\title{
O ESPÍRITO ENCARNADO: EXPRESSÃO E TRANSCENDÊNCIA NA OBRA DE Paul Cézanne
}

\author{
[THE INCARNATE: SPIRIT EXPRESSION AND TRANSCENDENCE IN THE WORK OF PAUL CÉZANE]
}

\author{
Tiago de Jesus Sousa * \\ Universidade Federal do Amazonas, Brasil
}

\begin{abstract}
RESUMO: Nesse artigo nos propomos pensar a noção de espírito encarnado em Merleau-Ponty e a pintura de Paul Cézanne em contato direto com o mundo bruto e vertical, o que proporciona, a partir da criação, o contato com o ser e sua possibilidade de transcendência pela expressão. Essa discussão considera a possibilidade de pensar uma nova via de investigação filosófica que tome como modelo a pintura e a transcendência da obra de Cézanne, de modo que a filosofia se assente no solo prévio de todo conhecimento que é a própria expressão do ser e se configure enquanto latência e abertura.
\end{abstract}

Palavras-chave: Espírito, carne, mundo, ser, pintura.

\begin{abstract}
In this article we propose to think of the notion of spirit embodied in Merleau-Ponty and Paul Cézanne's painting in direct contact with the raw and vertical world, which provides, from creation, contact with being and its possibility of transcendence through expression. This discussion considers the possibility of thinking about a new path of philosophical investigation that takes Cézanne's painting as a model and transcends the work, so that philosophy is based on the previous soil of all knowledge that is the very expression of being and is configured while latency and openness.
\end{abstract}

KEYwords: Spirit, flesh, world, being, painting.

\section{INTRODUÇÃO}

Daul Cézanne (1839-1906) é considerado por muitos o pai da pintura moderna, foi tomado como uma referência para seus contemporâneos e se tornou um marco para aqueles artistas que vieram depois do seu tempo. Nascido numa ruela de Aixen-Provance, na França, filho de um chapeleiro que fez fortuna a ponto de criar um banco, viu nascer desde cedo o desejo de tornar-se artista. Entretanto, esse desejo foi inicialmente frustrado por seu pai, Louis-Auguste, que desejava que o filho assumisse seus negócios. Foi em 1856, quando entrou na École de dessin de la Place de SaintJean-de-Malte, ainda em seu período de estudos escolares que solidificou a ideia de tornar-se pintor. A resistência de seu pai o impulsionou a frenquentar a faculdade de direito, mas em meio a sua insistência Louis-Auguste, por fim, cede ao desejo do jovem Cézanne e financia seus estudos de arte em Paris.

Sua obra rompe com o ideal clássico de beleza e transforma a pintura, que era até então considerada sinônimo de representação e perfeição mimética. Apesar de estar

* Professor do Instituto de Saúde e Biotecnologia da Universidade Federal do Amazonas Campus Médio Solimões. E-mail: tjsousa@ufam.edu.br 
próximo ao movimento impressionista e por vezes ser considerado um deles, sempre usou sua palheta para afastar-se dos conceitos rígidos que exigiam daquele movimento. Foi duramente criticado por mostrar uma obra chocante e de difícil digestão para uma sociedade enraizada num ideal de arte marcada pelo renascimento e, talvez por isso, só teve grande reconhecimento pouco antes de sua morte. A originalidade de sua pintura era apontada, justamente, como seu fracasso por aqueles que ainda não podiam prever a potencialidade da obra e a ruptura dos paradigmas nas artes que aconteceria ali por diante.

Neste artigo, nos manteremos no horizonte filosófico da obra de Maurice Merleau-Ponty, que apontou a pintura de Cézanne como um modelo de superação de uma visão dualista do mundo e como um guia para a filosofia, confrontando a noção de idealista de espírito. Nesse trajeto, iniciamos com o modo como Merleau-Ponty nos aponta a pintura do mestre de Aix: paradoxal, o que já nos permite dizer que ela não opera em favor de um espírito universal ${ }^{1}$, absoluto e de uma razão acabada como veremos a frente. Merleau-Ponty quer mostrar que Cézanne, que é homem como todos os outros homens, é capaz de perceber a natureza de uma maneira primordial antes mesmo de qualquer teorização, e isso pode ser encontrado em sua obra de maneira clara. "Entregue a si mesmo, ele pôde olhar a natureza como somente um homem pode fazê-lo"(MERLEAU-PONTY, 2004, p. 128). Cézanne não é um privilegiado, ele tem diante de si o mundo e pinta-o. $\mathrm{O}$ modo de perceber o mundo em Cézanne não é diferente para aquele que não é pintor, entretanto, o hábito de subjugar a percepção a uma operação racional nos encobre o mundo que é desvelado na obra do pintor. Esse desvelamento não se configura numa transcendência aos moldes idealistas, onde o sujeito epistemológico separa-se do corpo como um espírito absoluto ou ainda, não se atrela à possibilidade de um conhecimento a priori que torna possível a experiência. Ao contrário, o espírito aqui é pura expressão de um corpo encarnado no mundo e que adere a esse mundo por fazer parte dele.

\section{O ESPÍRITO DO PINTOR: UMA EXPRESSÃO DO CORPO}

Todo homem, como Cézanne, é um privilegiado porque percebe a ordem espontânea das coisas, mas Cézanne se reconhece no mundo e liga-se a ele de uma maneira que pode percebê-lo no seu contato primeiro, e assim pinta-o. Ele não leva em conta as predicações racionais que são frutos de um espírito idealista, que tudo vê e que toma posse das coisas e do mundo como se fosse sua própria criação, sem perceber que depende da natureza que se apresenta ao homem primordialmente.

A pintura de Cézanne é espiritual no sentido em que promove o ser e cria um mundo onde não há semelhanças, mas expressão. Não chamaremos aqui esse espírito de interior, como o faz Kandinsky(1996, p. 53), mas de expressão do corpo, que emana do contato com o mundo e proporciona a obra, viva nas cores e na tela do artista.O espírito que brota na obra de Cézanne não invalida a percepção nem tão pouco impossibilita a experiência do mundo. Não há, em sua pintura, uma dependência de qualquer faculdade que inaugure uma representação anterior à vivência do mundo, isso porque é o corpo do pintor que possibilita a experiência, e é no tecido do mundo que se dão todas as significações humanas.

"Cézanne dizia que um quadro contém em si até o odor da paisagem. Ele queria dizer que o arranjo da cor na coisa (e na obra de arte ela retoma totalmente a coisa) significa por si mesmo todas as respostas que ela daria a uma interrogação dos outros sentidos, que uma coisa não teria essa cor se não tivesse também essa 
forma, essas propriedades táteis, essa sonoridade, esse odor, e que a coisa é a plenitude absoluta que minha existência indivisa projeta diante de si mesma."(MERLEAU-PONTY, 2011, p.427)

$\mathrm{O}$ homem, que faz parte do mundo, mantém um extrato de corporeidade que conserva uma promiscuidade absoluta com o mundo e que carrega consigo os sentimentos, a história e a vivência, um passado e um futuro que decorrem dessa relação viva que brota diante dele. É nesse extrato do corpo que se manifesta o espírito do artista, "o espírito se vê e se lê nos olhares[...] se oferecem a nós encarnados, aderidos a um rosto e a um gesto"(MERLEAU-PONTY, 2004, p. 135). O espírito não é uma coisa diferente do corpo, essa experiência é encarnada e primordial e não admite separações, "é um campo de presença - presença a si, presença a outrem e ao mundo e porque esta presença o lança no mundo natural e cultural a partir do qual ele se compreende"(MERLEAU-PONTY, M. 2011, p. 605).

Não é possível afastar-se do corpo na medida em que não sou apenas uma coisa, ou como define a biologia, um qualquer punhado de relações fisico-quimícas, há um horizonte de significações de uma realidade perante o mundo que reconhece o espírito como "um fato inalienável, e [que] elimina qualquer espécie de idealismo revelando-me como 'ser no mundo'.”(MERLEAU-PONTY, M. 2011, p. 9). É preciso deixar claro que não se fala em espírito absoluto. O sentido de espírito, como já dissemos, é inseparável do corpo e do mundo, ele é formado a partir da relação das experiências e da unidade entre subjetividade e intersubjetividade. Portanto, não é esse o espírito objetivo que só se encontra nas reentrâncias de uma consciência isolada, se assim o fosse, a percepção de Cézanne estaria fadada ao empobrecimento e sua pintura seria apenas uma operação racional. Mas ao contrário, o mundo humano é "o meio e como que a pátria de nossos pensamentos"(MERLEAU-PONTY, M. 2011, p. 50).

Para pintar é preciso se reconhecer como corpo, e para tal não é necessário uma síntese mental. É só vivendo o corpo que podemos verdadeiramente conhecê-lo, ser corpo é pois transpassar-se, "é estar atado a um certo mundo"(MERLEAU-PONTY, M. 2011, p. 205) e assim, a experiência não será efetuada por uma idéia, mas pela realidade. Merleau-Ponty nos indica uma proposta de irredutibilidade do corpo, de superação de uma dicotomia que separa o espírito e o corpo, o sujeito e o mundo. Nesse sentido, a pintura clássica estaria impregnada das concepções racionais que fundaram suas obras. A disposição espacial euclidiana, a geometria e a racionalidade como fontes de conhecimento do mundo tomaram o papel de um mundo que é primeiro e apresentase ao pintor em toda sua imperiosidade que é exigida na criação.

O pintor que pensa e que busca a expressão não alcança de início o mistério, renovado toda vez que olhamos alguém, de seu aparecimento na natureza. [...] Vivemos num meio de objetos construídos pelos homens, entre utensílios, em casas, ruas, cidades e, na maior parte do tempo, não os vemos senão por meio das ações humanas das quais eles podem ser os pontos de aplicação. Habituamo-nos a pensar que tudo isso existe necessariamente e é inabalável. A pintura de Cézanne suspende esses hábitos e revela o fundo de natureza inumana sobre o qual o homem se instala. Por isso seus personagens são estranhos e como que vistos por um ser de outra espécie. A própria natureza é despojada dos atributos que a preparam para comunhões animistas: a paisagem é sem vento, a água do lago de Annecy sem movimento, os objetos transidos parecem hesitantes como na origem da terra. É um mundo sem familiaridade, no qual não estamos bem, que impede toda efusão humana (MERLEAU-PONTY, M. 2004, p. 135-136).

A pintura de Cézanne provoca essa falta de familiaridade porque alcança o mistério, esse mistério que é manifesto no contato direto com o mundo e que o 
pensamento suprime a partir de uma reflexão que não retorna ao mundo.

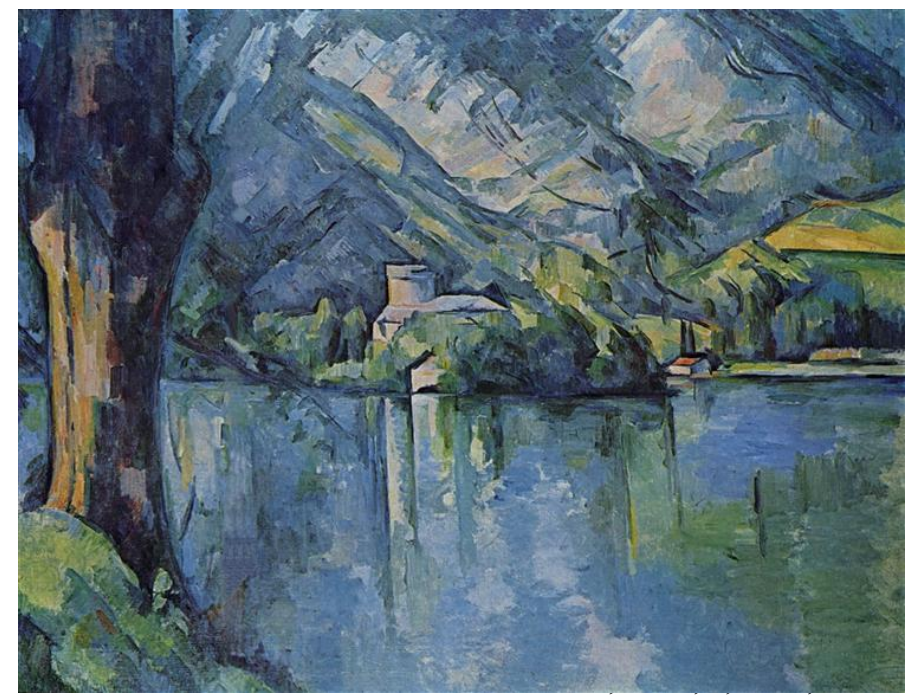

C Courtauld Gallery, London, UK

No início da Fenomenologia da Percepção, Merleau-Ponty recobra Husserl (MERLEAU-PONTY, M. 2011, p. 6) para propor um retorno às coisas mesmas e ao mundo da vida. $\mathrm{O}$ objetivo parece ser superar a universalização e a apreensão objetiva das coisas que se constituem a partir de um espírito que está destituído do corpo e não se relaciona com o mundo. Quando o pintor supera esse sentido objetivo e realiza sua obra a partir da experiência própria do mundo, ele vive a experiência de uma maneira total, mas não alcança a totalidade e exatidão do mundo porque essa experiência perceptiva é sempre uma experiência dada pelo contato motor do corpo no mundo de uma maneira originária e não por um movimento da consciência. E justamente por isso, "a arte não é nem uma imitação, nem uma fabricação segundo os desejos do instinto ou do bom gosto. É uma operação de expressão" (MERLEAU-PONTY, M. 2004, p. 137).

É preciso que se deixe de lado aquela experiência de corpo que se dá através da ideia de corpo. Essa ideia não é completa e é sempre segunda, "meu corpo é um sujeito natural" (MERLEAU-PONTY, M. 2011, p. 269) e o pensamento não pode nunca tomar o lugar da experiência viva. O corpo e o espírito do artista, do homem, são uma totalidade já que ser-no-mundo é ser corpo e é, ao mesmo tempo, estar atado ao mundo de uma maneira que um confunde-se com outro. Também por isso, o espírito (que chamamos aqui anteriormente de expressão do corpo) permanece a todo tempo no horizonte da percepção, ele não se desagarra nunca do corpo, é também corpo. Dessa forma, a pintura é a realização de uma "totalidade comportamental"(CAMINHA, 2010, p. 298) que se faz por uma composição da unidade do corpo e do mundo pelo sujeito encarnado, do verdadeiro sujeito da percepção (MOUTINHO 2004). A ação pictórica se dá a partir de ações habituais no espaço corporal em que o corpo do pintor está situado e não numa intenção de conhecimento.

Kandinsky $\operatorname{diz}(1996$, p. 28) que o nascimento da obra se dá a partir do cérebro do artista que, depois de viver "uma experiência completa" entrega-a ao espectador. 
Esse fisiologismo não leva em conta o contato com o mundo para que a expressão venha à tona, ele atribui ao espírito absoluto uma condição de necessidade de produção que foge a verdadeira rotina da experiência perceptiva. Na verdade, o mundo que Cézanne pinta é o mundo que nós ignoramos e que sempre está aí, diante de nossos olhos, que é revelado pela experiência perceptiva e que vivemos a todo tempo.

Kandinsky ainda nos aponta uma ilustração em forma de triângulo para demonstrar a vida espiritual do artista, segundo ele, esse triângulo é divido horizontalmente em partes que avançam de baixo para cima. No topo estão os gênios, aqueles artistas que estiveram a frente de seu tempo, que compreenderam a dinâmica da vida espiritual e aquilo que ele chama de progresso (KANDINSK, 1996, p. 28). Já o vimos, o espiritual que elegemos nesse artigo, aparta-se desse conceito idealista de uma separação do corpo e do mundo, por isso, o espiritual a que Kandinsky se refere não é a expressão do corpo, mas a representação mental.

Sobre Cézanne, o autor diz que sua tarefa foi encontrar o conteúdo interior nas formas exteriores, "não é nem um homem, nem uma maçã, nem uma árvore que Cézanne quer representar; ele serve-se de tudo isso para criar uma coisa pintada que proporciona um som bem interior e se chama imagem"(KANDINSK, 1996, p. 53). Ora, é certo que a pintura de Cézanne não é representação, mas tão pouco é apenas uma imagem derivada da natureza. $\mathrm{O}$ próprio pintor responde que enquanto os clássicos faziam quadros, ele tentaria sempre fazer um fragmento da natureza (MERLEAUPONTY, M. 2004, p. 130).

Cézanne não acreditou ter que escolher entre a sensação e o pensamento, como entre o caos e a ordem. Ele não quer separar as coisas fixas que aparecem ao nosso olhar e sua maneira fugaz de aparecer, quer pintar a matéria em via de se formar, a ordem nascendo por uma organização espontânea[...] Foi esse mundo primordial que Cézanne quis pintar e por isso seus quadros dão a impressão da natureza em sua origem(MERLEAU-PONTY, M. 2004, p. 131-132).

O mestre de Aix interroga o mundo, ele não sai de si mesmo para encontrar o motivo em uma realidade superior ou numa realidade interior do objeto, seu único guia é a própria "natureza na impressão imediata"(MERLEAU-PONTY, M. 2004, p. 130). É o olho do artista que permite que o quadro seja mundo, a realização do quadro se configura a partir do contato primeiro com o mundo, é esse contato a fonte primária de significação do real, nesse contato não há divisões entre espírito e corpo ou sujeito e mundo. Nesse contato primordial com o mundo o pintor reconhece a ordem das coisas, é daí que as coisas nascem e aparecem diante dos olhos, de onde surge o motivo e de onde percebemos a inesgotabilidade da natureza e sua impossibilidade de compreensão absoluta. É aí que Cézanne percebe as deformações, os paradoxos e as incontingências do mundo da vida e assim pinta a natureza de uma maneira completamente autêntica. "Cézanne dizia que o pintor, diante de seu motivo vai encontrar-se com as mãos errantes da natureza"(MERLEAU-PONTY, M. 2011, p. 353) Seus quadros vibram de forma que a coisa vivida se irradia na tela e promove a descrição de um mundo bruto e primordial em toda sua profundidade.

Engajo-me com meu corpo entre as coisas, elas coexistem comigo enquanto sujeito encarnado, e essa vida nas coisas não tem nada de comum com a construção dos objetos científico. Da mesma maneira, não compreendo os gestos do outro por um ato de interpretação intelectual, a comunicação entre as consciências não está fundada no sentido comum de suas experiências, mesmo porque ela o funda: é preciso reconhecer como irredutível o movimento pelo qual 
me empresto ao espetáculo, me junto a ele em um tipo de reconhecimento cego que precede a definição e a elaboração intelectual do sentido (MERLEAUPONTY, M. 2011, p. 252).

Entrar em contato com a obra de arte não é fechar-me em mim mesmo. Estar diante de um dos quadros da Saint Victorie (FIGURA 2), pintados por Cézanne, não exige tapar os olhos e viajar a um mundo privado, assim também, para pintar aquela montanha o espírito do artista não alçou voo sobre ela para estudar em pensamento as nuances da montanha, mas o seu corpo a frequentou.

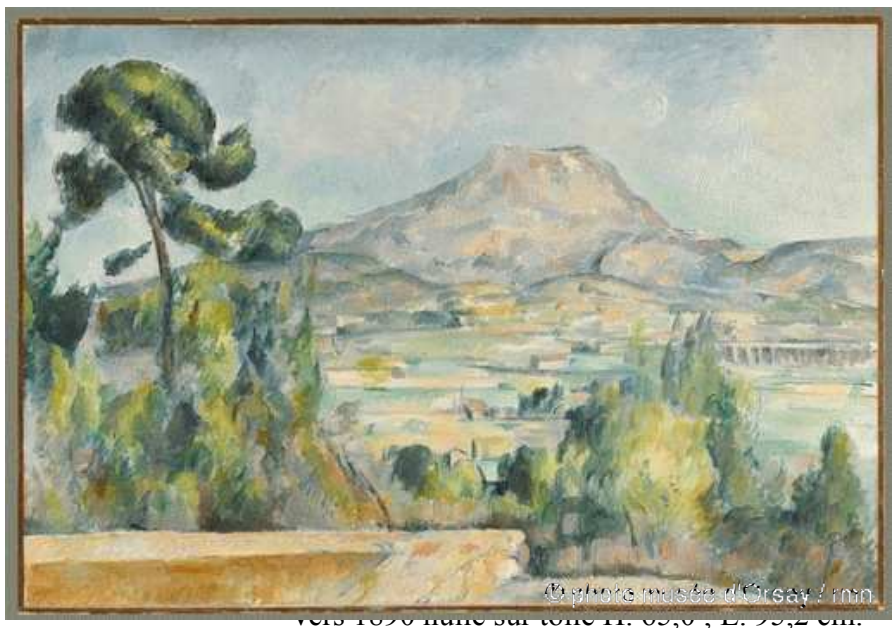

(C) Musée d'Orsay, Paris, France.

A partir da visão, o contato com a montanha se realiza de maneira inequívoca e ela se dá e se esconde em sua beleza, mas nunca se mostra por inteiro. É por habitarmos o mundo que a "nossa visão vai às próprias coisas"(MERLEAU-PONTY, M. 2003, p. 37) por meio de nossos corpos. Se ao fazer uma inspeção mental e me retirando do corpo, como exige o idealismo, pudesse fazer um inventário do quadro de Cézanne, o que encontraria que já não está lá? Como, afastando-me dele poderia compreendê-lo melhor e mais do que vendo-o?(MERLEAU-PONTY, M. 2003, p. 41) A essas perguntas, respondemos que não é preciso desfazer nossos vínculos originais com o mundo para compreendê-lo, assim como não é preciso afastar-se da obra para compreendê-la, a significação do quadro de Cézanne está no próprio quadro, como a significação do mundo está no próprio mundo. Por não sermos espíritos absolutos, há no real uma "infinidade de relações em cada um de seus momentos" (MERLEAUPONTY, M. 2004, p. 44) e, por isso também, não pode haver uma "suspensão da existência do mundo"(MERLEAU-PONTY, M. 2003, p. 168) na criação da obra de arte porque ela se dá no irrefletido, ela é um irrefletido. Assim, o campo fenomenal se converte em campo transcendental (MERLEAU-PONTY, M. 2011, p. 99), diferentemente da filosofia reflexiva que situa-se sempre e imediatamente em uma dimensão transcendental que não leva em conta o mundo da vida.

Cézanne pinta o contato com o mundo, expressa aquilo que existe no mundo 
(nunca de maneira acabada) transformando-o em um mundo próprio a partir da criação e não pode agir na introspecção de si mesmo porque sabe que o que o mundo oferece ao seu corpo é primeiro e anterior às teorizações que o objetivismo propõem. "Sua pintura é uma tentativa de encontrar a fisionomia das coisas e dos rostos pela restituição integral de sua configuração sensível” (MERLEAU-PONTY, M. 2011, p. 432). Isso explica a instauração da visibilidade que Cézanne promove. O pintor cria um mundo e restitui a originalidade da presença de um espírito encarnado no mundo, que não o tem em sua completude, mas que compartilha suas lacunas e seus paradoxos. Por isso o quadro não pode ser apenas uma imagem, mas "um mundo que se oferece à visão, um aparecer" (CAMINHA, I. 2010, p. 218). No pincel de Cézanne há a força de um despertar do visível, uma invenção do percebido "fazendo-se presença aos nossos olhos através do quadro" (CAMINHA, I. 2010, p. 223). O que vemos nos quadros de Cézanne não são rostos ou montanhas ou corpos ou maçãs, nem a imagem dessas coisas, vemos a expressão. "Existe ali um sentido latente, difuso através da paisagem[...] que reconhecemos em uma evidência específica sem precisar defini-lo"(MERLEAUPONTY, M. 2011, p. 378). Quando se diz que Cézanne busca encontrar o contato interior das coisas é como se o pintor retirasse antecipadamente a natureza do campo perceptivo para pintar, é como dizer que não existe valor real na experiência primordial do contado com o mundo. "A unidade da coisa para além de todas as suas propriedades físicas não é um substrato, um x vazio, um sujeito de inerência"(MERLEAU-PONTY, M. 2011, p. 427), mas uma resposta a interrogação da experiência que se dá de uma maneira única anterior à reflexão, de um modo de existência que se dá diante do pintor.

\section{CriaÇão E TRAnSCEndênCIA}

À margem de suas notas de trabalho, Merleau-Ponty diz que para o idealismo o espírito é a "passagem à idealidade como solução das antinomias"(MERLEAUPONTY, M. 2003, p. 38). No entanto, o mundo da vida é paradoxal e as coisas não são cogitatum. Do mesmo modo, o real não é uma derivação do pensamento e o espírito não é a fuga para uma realidade alternativa afastada do mundo, por isso mesmo há na vida uma impossibilidade de fuga do mundo, justamente porque só há um mundo, esse que está aí e no qual estamos atados na mesma trama e fazemos parte com a mesma carne.

A carne é o princípio fundamental do mundo da vida, criadora de unidade, princípio encarnado do ser. Se a perceção é promovida pelo corpo e existe uma estrutura intencional entre ele e o mundo, então há uma ligação sem a qual deixaríamos de ser sujeitos perceptivos. Esse aparecer do mundo e do sujeito perceptivo garante certas matrizes ativas e passivas do ser-no-mundo (VERÍSSIMO, 2014). A presença, a visibilidade e todas as dinâmicas da vida se dão no seu âmbito carnal, justamente porque a experiência do mundo é despertada em nós pelo nosso corpo (MERLEAUPONTY, M. 2011, p. 313) de modo que a percepção, que desvela o ser bruto, se faz do ponto de vista do organismo que é a carne (MERLEAU-PONTY, M. 2003, p. 89).

A pintura é transubstanciação entre o corpo do pintor e o corpo das coisas. Como é possível? É que a visão e o movimento são inseparáveis, embora diferentes: ver não é apropriar-se do mundo em imagem, mas aproximar-se das coisas, tê-las[...] $\mathrm{O}$ corpo é um enigma. Entre as coisas visíveis, é um visível, mas dotado do poder de ver-se quando vê, vê-se vendo, é um vidente visível para si mesmo (CHAUÍ, M. 2002, p. 177).

Enquanto vidente, o pintor tem no olhar a encarnação do ser, quando vidente, ele 
é ao mesmo tempo visível e esse desdobramento da visibilidade possibilita ao pintor estar entre as coisas, possui-las e ainda ser uma delas. A única distância possível a tal reversibilidade é o olhar, que permite a visibilidade através do corpo e mantém a espessura que chamamos de carne. Essa "reversibilidade compõe nossa experiência de mundo" (FURLAN, 2011, p. 113) e essa experiência é sempre anterior ao pensamento.

A pintura se liga ao seu sentido, ela indica uma relação entre o pintor e o motivo já que o mundo é abertura através da percepção e o motivo se oferece ao pintor que testemunha a dinâmica do mundo vivo. Não há uma visagem de qualquer paisagem mental no ato de pintar, mas tudo é oferecido pela natureza e por isso a pintura é um ato de expressão. Mesmo quando a pintura coloca em tela a expressão das emoções, ela as coloca através do gesto que contém, na própria expressão corporal, seu significado e que comunica "aos outros sujeitos encarnados" (MERLEAU-PONTY, M. 2011, p. 268).

Meu corpo é o lugar, ou antes a própria atualidade do fenômeno de expressão, nele a experiência visual e a experiência auditiva, por exemplo, são pregnantes uma da outra, e seu valor expressivo funda a unidade antepredicativa do mundo percebido e, através dela, a expressão verbal e a significação intelectual (MERLEAU-PONTY, M. 2011, p. 315).

Há no visível uma profundidade que exige a negatividade como matéria constituinte e, desse modo, abre uma dimensão no quadro que revela uma promiscuidade entre o artista e o mundo que revela também a própria experiência com o ser.

Este ser bruto selvagem será sempre ser de indivisão, carrega consigo a negatividade e a diferença, mas não é um puro negativo ou um puro positivo. É aquilo que permite a "distância interna entre um visível e outro que é o seu invisível" (CHAUÍ, 2002, p.154) Mas eles não são contrários, seja o visível e o invisível ou o negativo e o positivo, “o visível possui ele próprio, uma nervura de invisível, e o invisível é a contrapartida secreta do visível, não aparece senão nele" (MERLEAUPONTY, M. 2003, p. 200). Ou seja, o invisível se encontra no visível, está inscrito nele a partir de um distanciamento, de uma negatividade que sempre está aí instaurada.

Esse acontecimento consiste em que tal visível, convenientemente composto (um corpo), é rompido por um sentido invisível - O tecido comum de que são feitas todas as estruturas é o visível, que, ele próprio, não é, de modo algum, objetividade, em si, mas transcendência - que não se opõem ao para-si, que só tem coesão para um - Si - o Si a compreender, não como nada, não como algo, mas como unidade de transgressão, ou de imbricação correlativa de "coisa" e "mundo" (MERLEAU-PONTY, M. 2003, p.189).

Nesse sentido, o invisível não é negação absoluta e muito menos qualquer positividade absoluta, mas profundidade. De tal modo que não há que dizer que o negativo ou o positivo são contraditórios, na verdade, eles "são sinônimos" e "não por uma vaga mistura do ser e do nada, a estrutura não é mistura" (MERLEAU-PONTY, M. 2003, p. 216). Para Merleau-Ponty é a transcendência que explica o ser.

Cézanne não pode ser negatividade enquanto o mundo é positividade. Se assim o fosse, não haveria entrelaçamento, não haveria contato, o mundo seria o ser, e o pintor um nada, um si e um para si completamente vazios. Consequência de um ser "maciço" que não "permitiria encontro ou fricção". O nada e o ser devem ser idênticos, ou sinônimos como disse Merleau-Ponty, verso e anverso de um mesmo papel, "o direito e o avesso da mesma folha”, carne do mundo. Segundo Marilena Chauí (2002, p. 155156): 
A Carne do Mundo é o que é visível por si mesmo, dizível por si mesmo, pensável por si mesmo, sem, contudo, ser um pleno maciço, e sim, paradoxalmente, um pleno poroso, habitado por um oco pelo qual um positivo contém nele mesmo o negativo que aspira ser, uma falta no próprio Ser, fissura que se preenche ao cavar-se e que se cava ao preencher-se. Não é, pois, uma presença plena, mas presença habitada por uma ausência que não cessa de aspirar pelo preenchimento e que, a cada plenitude, remete a um vazio sem o qual não poderia vir a ser. A Carne do Mundo é o quiasma ou o entrecruzamento do visível e do invisível, do dizível e do indizível, do pensável e do impensável, cuja diferenciação, comunicação e reversibilidade se fazem por si mesmas como estofo do mundo.

Assim, o pintar não é um ato de apreensão como objeto, é uma abertura a si, "não é portanto alcançar-se, é ao contrário escapar-se, ignorar-se, o si em questão é de afastamento[...] portanto, não cessa de estar latente". O exame do motivo por Cézanne não é um pensamento de ver, é uma "experiência muda de um sentido mudo" (MERLEAU-PONTY, M. 2003, p. 226). Justamente por essa razão, a percepção do pintor o faz se abrir para o mundo, como quando abrimos uma janela e percebemos o horizonte em pleno funcionamento, "visto em sua atividade. É assim que o sensível me inicia no mundo". O pintor entrelaçado nesse mundo "desliza do subjetivo para o ser" (MERLEAU-PONTY, M. 2003, p. 202).

Certa relação entre o visível e o invisível, onde o invisível não é apenas nãovisível (o que foi ou será visto e não o é, ou aquilo que é visto por outro diferente de mim, não por mim), mas onde sua ausência conta para o mundo (ele está por detrás do visível, visibilidade iminente ou eminente[...]como uma outra dimensão) onde a lacuna que marca o seu lugar é um dos pontos de paisagem do "mundo". É este negativo que torna possível o mundo vertical (MERLEAUPONTY, M. 2003, p.209).

É a partir do mundo vertical que Cézanne pinta e desvenda o ser, é a partir da transcendência de uma identidade na diferença, onde o positivo e o negativo se fazem enquanto os dois lados do mesmo ser. Cézanne está em contato com o ser quando pinta porque faz parte desse tecido, enquanto pinta o mundo abre-se para ele e seu corpo abre-se para o mundo revelando uma deiscência que amplifica a relação de entrelaçamento de um corpo que é espírito encarnado e que não precisa sair de si para realizar-se enquanto estrutura do Ser posto que "as coisas visíveis são as dobras secretas de nossa carne e de nosso corpo"(MERLEAU-PONTY, M. 2003, p. 117). O horizonte nos rodeia e rodeia as coisas, por tanto, estamos no "horizonte do Ser"(MERLEAUPONTY, M. 2003, p. 216), um horizonte aberto que nunca cessa e que exige profundidade. Assim a pintura não pode ser uma tomada de consciência ou uma determinação de um espírito separado do mundo que carrega significados da natureza a partir de uma reflexão que se oferece como único critério de verdade. "Não há essências acima de nós, objetos positivos, oferecidos a um olho espiritual"(MERLEAU-PONTY, M. 2003, p. 117), "espíritos só se oferecem a nós encarnados, aderidos a um rosto e a gestos"(MERLEAU-PONTY, M. 2004, p. 135). Isso explica que a pintura não é um ato de apreensão privada de objetos, mas pura abertura a si e latência, é "escapar-se, ignorar-se, o si em questão é de afastamento [e] não cessa de estar latente"(MERLEAUPONTY, M. 2003, p. 226). O ser sempre se mostra em toda sua simultaneidade, e essa simultaneidade não espera um espaço horizontal de representação que será contemplado pelo pintor que ascende ao topo. Essa não é a única possibilidade de reconhecimento do 
mundo, nem mesmo é a primeira.

É a partir da expressão que Merleau-Ponty pode descrever a transcendência sem retornar a uma filosofia da consciência. "A encarnação, por sua vez, se bem pensada, afasta qualquer consciência” (MOUTINHO, 2015, p.68) por que ela mesmo promove a compreensão do corpo já que ela é razão de expressividade. Segundo Chauí, MerleauPonty está em busca do "Espírito Selvagem e o do Ser Bruto" (CHAUÍ, M. 2002, p. 151), disso decorre a premissa que sustenta que a criação promove o ser. Nesse interim, o artista que está diante da realidade do mundo, na espessura de sua carne, é solicitado pela visibilidade para trazer à tona o ser do visível. "A carne é 'transcendental', ou seja, ela não é apenas aquela transcendência que excede toda aparição, o originário que não pode ser intuído: porque é carne e não forma[...] e assim 'ser' se confunde com 'aparecer'”(MOUTINHO, L. 2015, p. 69).

Merleau-Ponty assinala que a novidade da arte moderna não é o surgimento do indivíduo, mas a comunicação com o Ser sem o apoio numa Natureza preestabelecida e fonte de paradigmas, um modo de sair da inerência e da fruição de si para aceder ao universal através do particular, encontrando na particularidade (o estilo) o meio para dar a ver e a conhecer a universalidade (o Ser que se exprime pela obra). Eis por que Merleau-Ponty, naquela mesma nota de trabalho, acentua que se trata da criação em sentido radical (CHAUÍ, M. 2002, p. 152).

Essa radicalidade criadora é a experiência de um mundo originário a partir do espírito selvagem do pintor "que não diz 'eu penso', e sim 'eu quero', 'eu posso"” (CHAUÍ, M. 2002, p. 152), já que ele mesmo é experiência de realização da obra que conduz à expressão. O ser selvagem é "intersubjetividade não perspectiva, mas vertical" (MERLEAU-PONTY, M. 2003, p. 171.) é o desvendar do invisível a partir de gestos, força e indivisão. Cézanne é um visível, um espectador contínuo do ser, essa experiência mundana mobiliza o preenchimento de lacunas que aparecem em sua experiência com o mundo, cheia de diferença e negatividade e permite ao pintor trazer à visibilidade um outro visível. "A filosofia, precisamente, como 'Ser falando em nós', expressão da experiência muda de si, é criação. Criação que é, ao mesmo tempo, reintegração do ser" (MERLEAU-PONTY, M. 2003, p. 187). Por conseguinte a transcendência é o aparecer, e na pintura de Cézanne ela se dá a partir da expressão do mundo, para Merleau-Ponty, uma tarefa infinita e inesgotável como os quadros de Cézanne.

\section{CONSIDERAÇÕES FINAIS}

Ao contrário do que nos fala Kandinsky, o triângulo não serve de ilustração para a experiência artística, não há um ponto de vista superior, não há um escalar do espírito para um topo onde, de maneira pura, o artista abarque as perspectivas do mundo, nem tão pouco há espíritos superiores. O espírito não se separa do mundo ou do corpo já que fazem parte da mesma carne. Há que se perceber que o ser é dado e se instala na ordem pré-empírica, não há uma pressuposição espiritual da natureza para ser dada como tema interior como supõe Kandinsky, mas uma tomada de posição a partir dela. A natureza é revelada pelo corpo e essa revelação só se dá a partir do vínculo do corpo com o mundo e não do espírito puro e objetivo. O triângulo carece de uma base abaixo dele, é lá que se encontra o gênio do artista antes de alçar-se a qualquer reflexão, no contato bruto com a natureza, em seu enraizamento com o mundo, no contato com o ser que não pode nunca ser reduzido a qualquer operação discursiva que só se solidifica a partir de uma 
inspeção do espírito absoluto.

É preciso que a filosofia encontre uma nova via de interrogação, que não mais se utilize dessa objetividade operante que tem o mundo como seu produto acabado e que acredita criar e dominar todas as coisas através de uma representação intelectual absoluta. Cézanne, esse espírito encarnado que se configura a partir da potência da ação no mundo da vida e de seu relacionamento com o Ser Selvagem é um modo de explicitar à filosofia a possibilidade de interrogar o mundo a partir da própria natureza primordial. O espiritual na pintura de Cézanne se liga diretamente ao mundo bruto, vertical, que proporciona a partir da criação o contato com o ser e sua possibilidade de transcendência pela expressão.É preciso ainda pensar que o sentido de uma obra não é determinado, ou seja, a pintura de Cézanne exige um inacabamento, a criação exprime o mundo da vida e por tanto a transcendência é a fundação de um ser de contato. A experiência do pintor é "experimentar o que em nós se vê quando vemos", (CHAUÍ, M. 2002, p. 167) é “o Ser falando em nós” (MERLEAU-PONTY, M. 2003, p. 187), por isso a pintura é inscrição no ser, ela não é uma fabricação objetiva de um espírito puro que desgarra do corpo, mas adequação e contato, promiscuidade da carne que promove a transcendência.

\section{REFERÊNCIAS}

BARBARAS, Renaud. Le désir et la distance. Introduction à une phénoménologie de la perception. Paris: Vrin, 1999.

CAMINHA, Iraquitan de Oliveira. $O$ distante próximo e o próximo distante: corpo e percepção na filosofia de Merleau-Ponty. João Pessoa: Editora UFPB. 2010

CHAUI, Marilena. A experiência do pensamento: ensaios sobre a obra de Merleau-Ponty. São Paulo: Martins Fontes, 2002

DESCARTES, René. Descartes Trad: Enrico Corvisieri. São Paulo: Abril Cultural, 1983 (Coleção Os Pensadores)

FURLAN, Reinaldo. Carne ou afecto: fronteiras entre Merleau-Ponty e Deleuze-Guattari. $<$ https://revistas.ufpr.br/doispontos/article/viewFile/21513/19589> Curitiba: Dois Pontos, Vol. 8, n.2, p.99-130, 2011

KANDINSK, W. Do espiritual na arte. São Paulo: Martins Fontes, 1996

MERLEAU-PONTY, Maurice. O olho e o espirito. São Paulo: Cosac Naify, 2004

MERLEAU-PONTY, Maurice. O visivel e o invisivel. São Paulo: Editora Perspectiva. 2003

MERLEAU-PONTY, Maurice. Fenomenologia da percepção. São Paulo: Martins Fontes, 2011

MOUTINHO, L. O sensivel e o inteligivel: Merleau-Ponty e o problema da racionalidade. $<$ http://www.scielo.br/scielo.php?script=sci_arttext\&pid=S0100$512 X 2004000200005 \& \operatorname{lng}=$ en $\& n r m=$ iso $>$ Kriterion vol. $45 \mathrm{n}^{\circ} 110$. Belo Horizonte, 2004

MOUTINHO, L. De Merleau-Ponty a Barbaras. <https://doi.org/10.11606/issn.24479012.espinosa.2012.89468> Cadernos Espinosianos XXVII, 2015

SOUSA, Tiago de Jesus. A pintura de Paul Cézanne como expressão de presença em MerleauPonty. <https://repositorio.ufpb.br/jspui/handle/123456789/14117> 25/07/2018. 122 páginas. Dissertação de mestrado. Mestrado em Filosofia Centro de Ciências Humanas Letras e Artes, Universidade Federal da Paraíba, João Pessoa, 2018

VERÍSSIMO, Danilo Saretta. Percepção e impercepção: a experiência sensível na tradição fenomenológica. Psicol. Pesq., Juiz de Fora, v. 8, n. 2, p. 211-220,dez. Disponível em<http://pepsic.bvsalud.org/scielo.php?script=sci_arttext\&pid=S1982-

$12472014000200010 \& \operatorname{lng}=$ pt\&nrm=iso $>2014$.

\section{Notas}


1 Um espírito universal e objetivo não admitiria nunca paradoxos na sua constituição. Podemos notar essa disposição na necessidade da exclusão de todas as dúvidas quando Descartes nos apresenta as distinções entre coisa extensa e coisa pensante e seu percurso metodológico para chegar a verdade. Toda dúvida, e tudo que não for claro e distinto não pode participar do espiritual e por isso o corpo deve ser separado do sujeito enquanto espírito. A isso deriva a necessidade de existência de dois modos antagônicos, seja como consciência ou como coisa. Por isso, uma pintura paradoxal que não se eleva ao nível claro e distinto do espírito não pode ter existência já que a garantia da existência só se dá pela consciência e nunca pelo corpo, que segundo Descartes é apenas um vetor que não participa do processo do conhecimento. (Cf. DESCARTES, 1983, p.119) 